DOI: https://doi.org/10.47405/mjssh.v5i6.424

\begin{tabular}{|c|c|}
\hline 4 & Malaysian Journal of Social Sciences and Humanities (MJSSH) \\
\hline $\begin{array}{l}\text { Malaysian Journal of } \\
\text { Social sciences and }\end{array}$ & Volume 5, Issue 6, June 2020 \\
\hline (MJ-SSH) & e-ISSN : 2504-8562 \\
\hline & $\begin{array}{l}\text { Journal home page: } \\
\text { www.msocialsciences.com }\end{array}$ \\
\hline
\end{tabular}

\title{
Social Capital and Subjective Well-Being in Malaysia
}

Norafisha Kamarudin' ${ }^{1}$, Siew Hwa Yen ${ }^{1}$, Kok Fong See ${ }^{1}$

${ }^{1}$ School of Distance Education, Universiti Sains Malaysia (USM)

Correspondence: Norafisha Kamarudin (noranif98@yahoo.com)

\begin{abstract}
The objective of this paper is to examine the relationship between different forms of social capital and subjective well-being in Malaysia. Subjective well-being is observed based on two aspects: happiness and life satisfaction. The analysis using data from the World Value Survey with 1300 respondents. Based on the ordered probit regression analysis, it is found that bonding and linking social capital contribute to happiness. Happiness also increases for those who are more active in associations. However, bridging social capital based on trust of people from other religion and ethnic group as well as people whom an individual does not know have adverse contribution to happiness. Only linking social capital has a positive relationship with life satisfaction. In terms of religiosity, importance of God seems to have positive relationship with both happiness and life satisfaction. Other factors such as health status, income, marital status and education also have the influence on Malaysians' happiness and life satisfaction levels.
\end{abstract}

Keywords: happiness, life satisfaction, bonding social capital, bridging social capital, linking social capital

\section{Introduction}

Earlier studies on economics of happiness focused on relationship between income and happiness. World Happiness Report (2018) reveals that the happiest country in the world is Finland, followed by Norway and Iceland. It is stated that all the top ten happiest countries are among the countries which have highest income. This outcome brings to a positive correlation between income and happiness. However, income alone is not sufficient enough to measure one's well-being. For example, United States which is known as the wealthiest country in the world is not in the top ten ranking. As propagated by Easterlin $(1974,1995)$, the levels of well-being do not seem to be increasing with the increase of income, which is known as the "Easterlin Paradox". It concludes that economic growth is positively related to well-being only in short term.

Although Gross Domestic Product (GDP) is associated with well-being at one period, the correlation seems to fade as time goes by. In fact there are other elements out there that contribute to the wellbeing, such as social support. Social capital, as the determinant of subjective well-being slowly takes place after GDP. Social capital is defined as the network of people who live and work in a society and enables that society to function effectively. Social capital refers to trust, social norms and networks, and is spaciously recognized in the literature as an important element to increase the economic and social development (Coleman, 1988). 
Emile Durkheim, a sociologist from France, stated that socializing and being connected would bring benefit to human beings will prevent a person from a negative situation (Kroll, 2011). Due to lack of social capital, people are not able to make themselves comfortable or stable as they do not have enough support from the people around them. High social capital among neighbours or communities could lead to high subjective well-being due to the moral support from each other and would improve the function of society. Putnam (1995, p. 67) defined social capital as "features of social life networks, norms and trust that enable participants to act together more effectively to pursue shared objectives". Coleman stated that "social capital is defined by its function. It is not a single entity but a variety of different entities having two characteristics in common: they all consist of some aspect of social structure, and they facilitate certain actions of individuals who are within the structure" (Coleman 1990, p. 302).

Well-being is used spaciously in happiness studies, ranging from individual's happiness to satisfaction of needs (Ro-yo \& Velazco, 2006). There are two aspects of subjective well-being: life satisfaction and happiness. These two terms are used interchangeably among researchers (Easterlin, 2001; 2003; Ng, 2003; Frey \& Stutzer, 2002; Frey, 2008). Studies on economics of happiness and life satisfaction were mostly carried out in the Western countries, thus it should also be focused on non-Western countries which are in the process of developing (Selin \& Davey, 2012).

The World Happiness Report 2018 (Bedi, 2019) has recognized Malaysia to have happier society when it is ranked as the $35^{\text {th }}$ happiest country out of 156 countries. The recognition is based on the uniqueness of Malaysia as a multiracial country where the unity among the people can clearly be seen regardless of their races, religions and the standard of living. A study by Howell \&Howell, Wan and Ryan (2012) shows that the increase of health among Malaysians could increase the happiness, while better financial leads to increase in life satisfaction. Other factors such as gender, age, marital status, religiosity and education were also found to have influence on happiness and life satisfaction levels.

The objective of this study is to examine the relationship between subjective well-being and different types of social capital. Subjective well-being is observed from two aspects: happiness and life satisfaction. Thus, the influence of the three main types of social capital, bonding, bridging and linking social capital, on both happiness and life satisfaction will be examined in two separate models.

Besides different types of social capital, other factors such as income, health status, religiosity, marital status, educational levels and ethnicity are also taken into consideration in the analysis. This paper is divided into four sections: literature review; data and methodology; results and discussion; conclusion.

\section{Literature Review}

Social capital exists in our daily lives at every level of society. It is defined as the network of relationship among people who live and work in a particular society. It is also defined as "the capacity of individuals to command scarce resources by virtue of their membership in networks or broader social structures" (Portes, 1988). Through his research, Putnam proved that communities who engage with more social capital would function better. 'Strong ties with intimate friends may ensure chicken soup when you're sick' (Robert Putnam 2000, p. 323). Besides being important to the effectiveness of individuals and communities, social capital also has a powerful impact on health as well. Based on the previous findings, the exist of social capital in society can create higher impression of well-being (Helliwell, 2002).

Social scientists categorized three types of social capital based on relationship at different levels: bonding social capital, bridging social capital and linking social capital. Bonding social capital exists in a group of people who are similar in some ways such as family members, close friends and neighbours. Bridging social capital exists in individuals who are not similar in socioeconomic and other characteristics such as different in background, age or gender. Linking social capital refers to the relationship between different social power or authority in different strata where power, wealth and social status are accessed by different groups. 
Well-being is an important phenomena in living lives. Many social scientists have researched whether happiness plays such as important role to mankind. The term subjective well-being is often used with 'happiness' and 'life satisfaction' in the literature. Happiness is the effective and volatile element, while life satisfaction is a stable and evaluative process that correlates with long life (Diener 1984; Krueger and Schkade 2008). Happiness is measured by asking people to evaluate a certain life domain such as work and family by using multiple-item or single-item questions. A commonly used question in measuring happiness which also being used by the World Value Survey (WVS) is "Taken all things together, would you say you are: 1. very happy, 2. pretty happy, 3. not too happy." (Diener, 2009; Sarracino, 2010). Life satisfaction is defined as "the way in which people show their emotions and feelings and how they feel about their directions and options for the future" (Anand and Paul, 2016). Question taken from World Value Survey is "All things considered, how satisfied are you with your life as a whole these days?". Respondents can rate themselves on a scale from 0 (completely dissatisfied) to 10 (completely satisfied).

The relationship between social capital and happiness was found to be positive at individual level due to support and sharing among the community. Through the international well-being data, Helliwell (2003) suggested that differences in well-being can be explained by differences in social capital. Mohammad Ghamari (2012) conducted an empirical study on high school students of Karaj City to investigate the relationship of social capital and happiness on 318 students. The result showed that there is a positive relationship on social capital and happiness. A survey was conducted by Woo and Kim (2017) to examine the impact of social capital on life satisfaction among Asians, specifically in South Korea and Taiwan with 978 respondents. Considering health condition, social status and belief, the result showed that social capital has a positive impact on life satisfaction in Taiwan.

Matsushima and Matsunaga (2015) carried out a study in Japan on what type of social capital relate to one's subjective well-being. They result shows that overall, social capital has a positive relationship with subjective well-being. Trust and volunteering correlate positively with one's subjective wellbeing, whereas membership in organizations does not. Trust is an important indicator in measuring social capital and community with trust among themselves will improve their way of lives.

Dolan et al. (2008) carried out a study on more than 80 countries and the outcomes showed a positive relationship between trust and subjective well-being. Nadeem and Ankitha (2017) conducted a survey to observe the relationship between interpersonal trust and happiness among young adults in Bangalore city, India. Three hundred respondent with age around 25 years old are involved. The result showed that there is a significant and positive correlation between interpersonal trust and happiness.

A study was carried out by Churchill and Mishra (2017) to investigate the associations among trust, social trust and subjective well-being in China. It was found that the effect of social capital on subjective well-being in China as a developing country is weaker compared to the effect of income.

Kanai (2015) carried out a survey in Japan on 11,814 respondents to see the effect of bonding and bridging social trust between gender on subjective well-being. The result showed that for female sample, both bonding and bridging social capital have positive effects on subjective well-being. On the other hand, male sample indicates that there is a negative effect between bonding and bridging social capital on subjective well-being.

Besides social capital, it was found that happiness and life satisfaction have important relationships with other external factors such as age, race, being employed, being married, healthy and having a religion. Williams (2003) claimed that married couples are healthier and have higher level of wellbeing than unmarried ones. According to Easterlin (2006), happiness is at the peak point during the age 18 to 51 and however will decrease after that. The U-shape relationship describes that life satisfaction is low at the age of 45 to 55. In terms of religiosity, a study by Okulicz-Kozaryn (2010) on 79 nations using the WVS data revealed that religious people have higher life satisfaction compared to the non-religious ones. 
Chen and Meng (2015) carried out a study to investigate the relationship of bonding, bridging and linking social capital and self-rated health among Chinese adults in China. They found that bonding and linking social capital are positively correlated with health at individual level. Whereas, bridging social capital has a positive relationship with health at community level.

Using probit analysis to generate self-rated happiness, Cheah and Tang (2013) conducted a survey on 398 Malaysians involving variables such as age, marital status, gender, education, employment status, income, ethnicity and health. It is found that marital status, ethnicity and education are significant in determining individual's happiness.

\section{Data and Methodology}

This study is carried out to examine the relationship of social capital and subjective well-being in Malaysia. The two elements of subjective well-being are happiness and life satisfaction. They are examined separately as factors that influence happiness and life satisfaction could be different. The data used to investigate social capital influence on happiness and life satisfaction in Malaysia are based on WVS wave 6 (note: As for wave 6, global survey were carried out between 2010 to 2014. For Malaysia it was carried out in 2012), with 1300 respondents nationwide.

Level of happiness and life satisfaction are the dependent variables. The level of happiness is measured using a scale from 1 to 4 according to four different responses of the respondents. The survey question on happiness in wave 6 read as: "Taking all things together, would you say you are 1: Very happy, 2: Rather happy, 3: Not very happy and 4: Not happy at all. Life satisfaction question from WVS will be "All things considered, how satisfied are you with your life as a whole these days?" Respondents are required to rate themselves on a scale from 0 (completely dissatisfied) to 10 (completely satisfied). In this study, these range was re-scaled to 1: Completely dissatisfied (1 to 4), 2: Dissatisfied (5 to 6), 3: Satisfied (7 to 8) and 4 (9 to 10) Completely Satisfied. This will standardize the range for happiness and life satisfaction which will allow easier comparisons to be made between the two models.

Factor analysis is used to reduce 23 social capital related items into components which could represent different types of social capital. This technique is useful in studies that involved many variables to measure a common factor where big number of variables can be reduced into fewer numbers of factors. In this study, factor analysis is being used to reduce all the 23 social capital related items into bonding, bridging and linking social capital factors. All the items are subjected to principal component analysis (PCA) using SPSS. PCA indicates components with Eigen values greater than one. Varimax rotation is used to facilitate the interpretation of factor loading and coefficients are used to obtain factor scores for the selected factors.

In this study, the dependent variables, happiness and life satisfaction, are ordinal in nature, thus, ordered probit model is suitable to be used (Greene, 2002). Here, the answer categories for happiness and life satisfaction levels are considered only ordinally comparable which means the distances between the categories are not assumed to be equal. Ordered probit assumes an underlying continuous dependent variable $\left(y^{*}\right)$ which is has a linear relationship with the independent variables $(x): y^{*}=\beta x+$ $\varepsilon$. This latent dependent variable (y) in this study is subjective well-being (happiness and life satisfaction) which are in ordinal categories $(\mathrm{y}=1,2,3$ and 4$)$. STATA is being used to analysis the ordered probit model in this study.

\section{Results and Discussion}

Table 1 describes the dependent variables happiness and life satisfaction among the 1300 respondents in this study. The mean or average value for happiness is 3.53 , which is very close to the level of "rather happy" (scale 3). Out of the 1300 respondents, 56.5 percent declare themselves as "very happy", 39.5 percent "rather happy" and 3.9 percent "not very happy". None of the respondents indicate that they are "not at all happy". 
DOI: https://doi.org/10.47405/mjssh.v5i6.424

Table 1 : Descriptive Statistics

\begin{tabular}{lccc}
\hline & Frequency & Percent & Cumulative \\
\hline Feeling of happiness: & & & \\
Not at all happy & 51 & 0 & 0 \\
Not very happy & 514 & 3.9 & 3.9 \\
Rather happy & 735 & 39.5 & 43.5 \\
Very happy & 1300 & 56.5 & 100.0 \\
Total & & 100.0 & \\
(mean=3.53) & & & \\
Life satisfaction: & 79 & & \\
Completely dissatisfied & 359 & 6.1 & 6.1 \\
Dissatisfied & 597 & 27.6 & 33.7 \\
Satisfied & 265 & 45.9 & 79.6 \\
Completely satisfied & 1300 & 20.4 & \\
Total & & 100.0 & \\
Mean =2.81 & & & \\
\hline
\end{tabular}

The level of life satisfaction, also based on scale 1 to $4,20.4$ percent of the respondents feel "completely satisfied", 45.9 percent "satisfied", 27.6 percent "dissatisfied" and only 6.1 percent show they are "completely dissatisfied" with their lives. There are higher percentage of Malaysian whom are dissatisfied with their lives (27.6\%) as compared to those whom are completely satisfied $(20.4 \%)$. The majority are just satisfied with life.

Factor analysis is adopted in this study to group 23 social capital items to identify different components of social capital. Elements of social capital such as trust in family, neighbours and government; confidence in police, army and courts and active or inactive membership in organizations were involved in the process of factor analysis. PCA indicates four components with Eigen values more than one. In social science studies, moderate communalities values of 0.56 and 0.7 are common and acceptable, any values less than 0.40 suggest that the item does not related to the other items in the same factor (Velicer and Fava, 1998). Communalities for all the four social capital components are within the range of 0.41 and 0.86 which indicate that all the items in each factor are related. The outcomes show that four components which could be represented by bonding, bridging (trust and associational life) and linking social capital were identified. Table 2 presents the 23 social capital items that have been categorized into the four components using factor analysis.

Table 2: Factor Analysis

\begin{tabular}{|c|c|c|c|}
\hline & Bonding-Trust Bridging-Trust & $\begin{array}{l}\text { Bridging- } \\
\text { Associational } \\
\text { Life }\end{array}$ & Linking \\
\hline $\begin{array}{l}\text { Active/Inactive } \\
\text { membership in: }\end{array}$ & & & \\
\hline $\begin{array}{l}\text { Church or religious } \\
\text { organization }\end{array}$ & & .602 & \\
\hline $\begin{array}{l}\text { Sports and recreational } \\
\text { organization }\end{array}$ & & .721 & \\
\hline $\begin{array}{l}\text { Art, music or educational } \\
\text { organization }\end{array}$ & & .706 & \\
\hline Labour Union & & .645 & \\
\hline Political party & & .613 & \\
\hline Environmental organization & & .784 & \\
\hline Professional Association & & .747 & \\
\hline Humanitarian or charitable & & .774 & \\
\hline
\end{tabular}




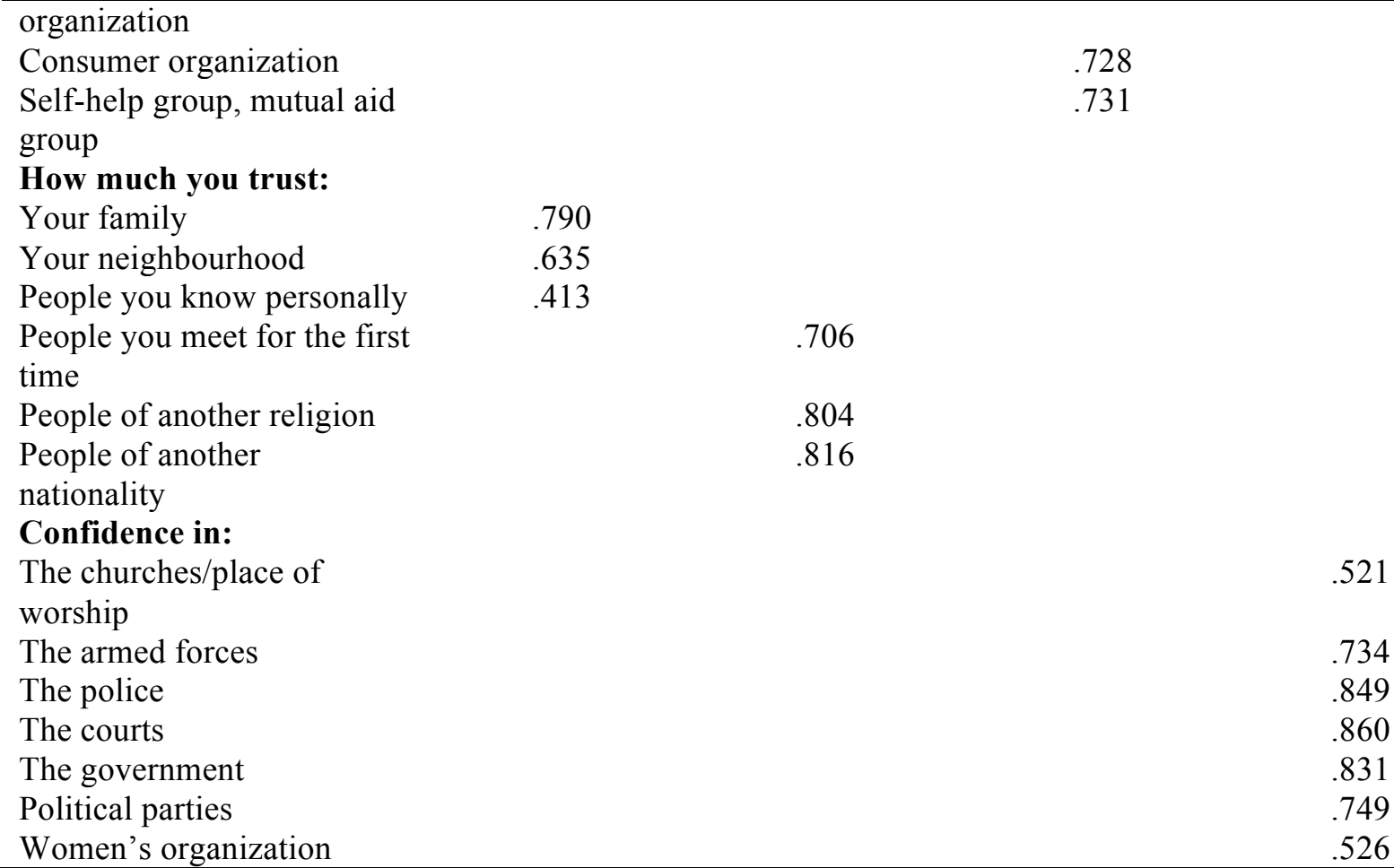

Bonding (Bonding-Trust) is represented by trust within family, neighbourhood and people we know. Linking social capital is embedded by confidence in police and arm forces, place of worship, judiciary system, government, political parties and women organization. Bridging social capital can be divided into two: Bridging-Associational Life and Bridging-Trust. Bridging- Associational Life consists of active or inactive membership in: church or religious organization, sports and recreational organization, art, music or educational organization, labour union, political party, environmental organization, professional association, humanitarian or charitable organization, consumer organization, self-help group and mutual aid. Bridging -Trust is named based on the trust given to people you meet at the first time, people of another religion and nationality.

\section{Happiness and Life Satisfaction Models}

Ordered Probit is introduced to analyze cases that have more than two outcomes of an ordinal dependent variable.

Table 3 shows the results of ordered probit regression on the impact of social capital and other sociodemographic factors on happiness. Bonding and linking social capital seemed to have significant contribution to happiness. Trust among family members, neighbourhood and people you met personally seem to have positive influence on happiness. Confidence in police, courts and government in linking social capital also have positive impact on happiness. Thus, higher bonding and linking social capital will bring to greater happiness among Malaysians.

Malaysians involved more actively in associations seemed to be happier. The reason is people who have social contacts may be happier compared to those who do not have them (Diener and Seligman, 2002). However, in general Malaysians are happy but they do not trust people from other religion and nationality. They also are cautious and do not trust people they first meet. A negative and significant relationship between happiness and bridging social capital based on trust shows that happier people may not have high bridging social capital particularly those that based on trust. 
DOI: https://doi.org/10.47405/mjssh.v5i6.424

Table 3: Estimated Ordered Probit on Happiness Model

\begin{tabular}{lll}
\hline Happiness & Coefficient & P-Value \\
\hline Types of Social Capital & & \\
TrustBond & .1131751 & $(0.001)^{* * *}$ \\
TrustBridge & -.0654902 & $(0.064)^{*}$ \\
AssocLifeBridge & .0606126 & $(0.089)^{*}$ \\
Linking & .2461269 & $(0.000)^{* * *}$ \\
Religiosity & & \\
Religious_Svc & .2807401 & $(0.000)^{* * *}$ \\
BelieveGod & .1780423 & $(0.536)$ \\
ImportanceofGod & .075755 & $(0.001)^{* * *}$ \\
Marital Status & & \\
Married & -.0239758 & $(0.810)$ \\
Divorced/separated/Widowed & -.0136798 & $(0.947)$ \\
HealthStatus & .6063187 & $(0.000)^{* * *}$ \\
Income & .1141514 & $(0.000)^{* * *}$ \\
Employment & & \\
Employed & .4856764 & $(0.056)^{*}$ \\
NotWorking & .4608026 & $(0.082)^{*}$ \\
Education Level & & \\
Primary & .1962553 & $(0.155)$ \\
Secondary & .2360416 & $(0.029)^{* *}$ \\
Age & .00012 & $(0.973)$ \\
Female & .0973946 & $(0.185)$ \\
Ethnicity & & \\
Malay & & \\
Chinese & -.0451194 & $(0.739)$ \\
\hline Notes: ***,** and * significant at $1 \%, 5 \%$ and $10 \%$ levels respectively &
\end{tabular}

Table 4 presents the results of the impact of social capital and other socio-demographic factors on life satisfaction. The outcomes show that only linking social capital has positive and significant contribution to life satisfaction of Malaysians. Thus, this study indicates that bonding and bridging do not increase their life satisfaction levels.

Table 4: Estimated Ordered Probit on Life Satisfaction Model

\begin{tabular}{lll}
\hline Life Satisfaction & Coefficient & \multicolumn{1}{c}{ P-Value } \\
\hline TrustBond & .0356561 & $(0.246)$ \\
TrustBridge & -.0416029 & $(0.174)$ \\
AssocLifeBridge & .0434978 & $(0.161)$ \\
Linking & .0991732 & $(0.002)^{* * *}$ \\
Religious_Svc & .0139589 & $(0.831)$ \\
BelieveGod & .6291608 & $(0.020)^{* *}$ \\
ImportanceofGod & .0570644 & $(0.007)^{* * *}$ \\
Married & .1721318 & $(0.050)^{* *}$ \\
Divorced/separated/Widowed & .2463488 & $(0.180)$ \\
HealthStatus & .4299017 & $(0.000)^{* * *}$ \\
Income & .1122878 & $(0.000)^{* * *}$ \\
Employed & .6012915 & $(0.011)^{* *}$ \\
NotWorking & .7611105 & $(0.002)^{* * *}$ \\
Primary & -.1845666 & $(0.131)$ \\
Secondary & -.002629 & $(0.978)$ \\
Age & .0018096 & $(0.566)$ \\
Female & -.0877492 & $(0.170)$ \\
Malay & .1551042 & $(0.183)$
\end{tabular}


Chinese .1244672

Notes: $* * *, * *$ and $*$ significant at $1 \%, 5 \%$ and $10 \%$ levels respectively

Being unemployed has significant adverse influence on the well-being of Malaysians. Similar to the happiness model, the life satisfaction model also indicates that respondents who are employed and not working are more satisfied with their lives compared to those who are unemployed. Believe in God and importance of God in their lives are both important in contributing to life satisfaction among Malaysians. Thus believe in God makes a person more satisfied with life but not necessarily happier.

Being married as compared to being singles has significant influence on life satisfaction. However, being divorced and separated compared to being single does not have significant influence on life satisfaction. Being married as compared to being single makes a person more satisfied with life.

People feel more satisfied when they are healthier. Income is one of the important factors that contribute to life satisfaction among Malaysians. People with higher income have higher levels of satisfaction compared to those with lower income. Both income and health status are important factors in influencing the well-being of Malaysians. Education level does not seem to have significant influence on life satisfaction.

\section{Conclusion}

Even though happiness and life satisfaction are sometimes used interchangeably to represent subjective well being, in Malaysia we found that different factors could influence them. This study also shows that different types of social capital have different influence on happiness and life satisfaction. The outcomes indicate that bonding social capital, which consists of trust among family members, neighbours and friends, has positive influence on one's happiness but no significant contribution to life satisfaction.

Bridging social capital, which consists of involvements in different types of associations, indicates a positive contribution to happiness. Both types of bridging social capital do not have significant influence on Malaysians' life satisfaction.

Linking social capital, which represented by confidence in religious bodies and crucial government's services such as security and judiciary, has significant positive influence on happiness and life satisfaction. Thus, only linking social capital has positive effects on Malaysians' both happiness and life satisfaction. Overall, all the three types of social capital: bonding, bridging and linking have influence on happiness but only linking social capital was found to have positive relationship in life satisfaction.

Religiosity, income, health and employment are common factors that contributed to subjective wellbeing represented by happiness and life satisfaction. Bonding and bridging social capital may not have influence on life satisfaction but other factors such as being married could make Malaysians more satisfied in life but not necessarily happier. Good health, higher income and being employed have significant impact on Malaysians' subjective well-being, in terms of happiness and life satisfaction.

In terms of religiosity, importance of God seems to have positive relationship with both happiness and life satisfaction. In general, Malaysians have less trust on people of other religion which mostly segregated by ethnic groups. This may have some implications on Malaysian society that consists of multi-ethnic groups.

\section{References}

Anand \& Paul. (2016). Happiness Explained. Oxford University Press. 
Bedi, R.S. (2019). World Happiness index: Malaysia plunges from no35 to 80 in one year. The Star. 21 March, 2019.

Cheah, Y.K., \& Tang, C.F. (2013). The social-demographic determinants of self-rated happiness: The case of Penang, Malaysia. Hitotsubashi Journal of Economics 54(1), 1-16.

Chen H, Meng T. (2015) Bonding, Bridging, and Linking Social Capital and Self-Rated Health among Chinese Adults: Use of the Anchoring Vignettes Technique. PLoS ONE 10(11): e0142300. doi:10.1371/journal.pone.014230.

Chong, S. T., Koh,D., Fauziah, I. \& Samsudin, A. R. (2017). Neighbourhood Social Capital and Neighbourhood Safety in Predicting the Subjective Well-being of Young Malaysians. Pertanika J. Soc. Sci. \& Hum. 25 (S): 155 - 164.

Churchill, S. A. \& Mishra, V. (2017). Trust, Social Networks and Subjective Wellbeing in China. Social Indicators Research,132, 313-339.

Coleman, J. M. (1988). Social capital in the creation of human capital. American Journal Sociology, 94, S95-S120.

Coleman, J. (1990). Foundations of Social Theory. Cambridge, Mass.: Belknap Press of Harvard University Press.

Diener, Edward. (2009). "Subjective Well-being." In The Science of Well-being: The Collected Works of Ed Diener. Edited by Ed Diener. Social Indicators Research Series 37. New York, NY: Springer Publishing.

Diener, E., \& Seligman, M. E. P. (2002). Very happy people. Research report. Psychological Science, 13(1), 81-84.

Dolan, P., Peasgood, T., \& White, M. (2008). Do we really know what makes us happy? A review of the economic literature on the factors associated with subjective well-being. Journal of Economic Psychology, 29, 94-122.

Easterlin, R.A. (1974). Does economic growth improve the human lot? Some empirical evidence. In David, P.A. and Reder, M.W. (Eds.), Nations and households in economics growth: Essays in honor of Moses Abramowitz. New York: Academic Press, pp.89-125.

Easterlin, R. A. (1995). Will raising the incomes of all increase the happiness of all? Journal of Economic Behavior and Organization 27, 35-47.

Easterlin, R.A. (2001). Income and happiness: Towards a unified theory. Economic Journal, 111(473), 465-484.

Easterlin, R.A. (2003). Building a better theory of well-being. IZA Discussion paper series, No. 742.

Easterlin, R.A. (2006). Life cycle happiness and its sources: Intersections of psychology, economics, and demography. Journal of Economic Psychology 27(4), 463-48.

Frey, B. S., \& Stutzer, A. (2002). What can economists learn from happiness research. Journal of Economic Literature, 40, 402-435.

Frey, B.S. (2008). Happiness: A revolution in economics. Cambridge, Mass: MIT Press.

Ghamari, M. (2012). The Relationship of Social Capital and Happiness among High School Students of Karaj City. International Journal of Academic Research in Business and Social Sciences, 2(1), 2222-6990.

Greene, W. H. (2002). Econometric Analysis. Fifth Edition. Prentice Hall. Upper Saddle River.

Howell. R.T., Chong, W.T., Howell, C.J., \& Schwabe, K. (2012). Happiness and life satisfaction in Malaysia. In Selin, H. \& Davey, G. (Eds.), Happiness across culture: View of happiness and quality of life in non-Western cultures. New York: Springer, pp.43-55.

Kanai, M. (2015). Contextual Effects of Bridging Social Capital on Subjective Well-being. The Senshu Social Well-being Review No.2.

Kroll, C. (2011). Towards a sociology of happiness: examining social capital and subjective wellbeing across subgroups of society. The London School of Economics and Political Science (LSE).

Krueger, A.B. and D. Schkade. 2008. The Reliability of Subjective Well-being Measures. Journal of Public Economics. 92, 1833-1845.

Matsushima, M. \& Matsunaga, Y. (2015). Social Capital and Subjective Well-Being in Japan. International Journal of Voluntary and Nonprofit Organizations, 26, 1016-1045. http://dx.doi.org/10.1007/s11266-015-9623-x.

Nadeem, M. \& Ankhita, U.(2017). Interpersonal Trust and Happiness among Young Adults: A Correlational Study. International Journal Of Public Mental Health and Neurosciences, 4(1). 
Ng, Y.K. (2003). From preference to happiness: Towards a more complete welfare economics. Social Choice Welfare 20(2), 307-350.

Okulicz-Kozaryn, A. (2009). Religiosity and life satisfaction across nation. Mental Health, Religion \& Culture, 13(2), 155-16.

Portes, A. (1998). Social capital: Its origins and applications in modern sociology. Annual Review of Sociology, 24, 1-24.

Paldam, M. (2000). Social capital: One or many? Definition and measurement. Journal of Economic Surveys, 14, 629-653.

Putnam, R.D. (1993). Making Democracy Work: Civic Traditions in Modern Italy. Princeton, NJ: Princeton University Press.

Putnam, R. D. (1995). Bowling alone: America's declining social capital. Journal of Democracy, 6, $65-78$.

Putnam, R. (2000) Bowling Alone: The Collapse and Revival of American Community. New York: Simon Schuster.

Royo, M.G., \& Velazco, J. (2006). Exploring the relationship between happiness, objective and subjective well-being: Evidence from rural Thailand. WeD Working Paper. United Kingdom: Economic and Social Research Council (ESRC) Research Group on Wellbeing in Developing Countries.

Sarracino, Francesco. (2010). "Determinants of Subjective Well-being in High and Low Income Countries: do happiness equations differ across countries?" CEPS/INSTEAD Working Paper 2010-15. Accessed: 29 May 2012. <http://ideas.repec.org/p/irs/cepswp/2010-15.html>.

Selin, H.\& Davey, G. (Eds.) (2012). Happiness across culture: View of happiness and quality of life in non-Western cultures. New York: Springer.

Velicer, W.F. \& Fava, J.L. 1998. Effects of variable and subjective sampling on factor pattern recovery. Psychological methods. 3: 231-51.

Williams, K. (2003). Perceived Housework Equity, Marital Happiness, and Divorce in Dual-Earner Households. Journal of Family Issues, 24(1). https://doi.org/10.1177/0192513X02238520.

Woo, M., \& Kim, S. (2017). Does social capital always raise life satisfaction? A comparison of South Korea and Taiwan. International Journal of Social Welfare. 27(2). https://doi.org/10.1111/ijsw.12293.

World Value Survey 2010-2014. Official Data File, v.20140428. World Value Survey Association. ASEP/JDS, Madrid. www.worldvaluesurvey.com [Accessed 20 September 2014]. 